\title{
A PREDICTIVE MODEL FOR SIMPLIFIED DISEASE ACTIVITY INDEX (SDAI) REMISSION IN RHEUMATOID ARTHRITIS
}

\author{
Cristina Pomirleanu ${ }^{1,2}$, Alexandra Jitaru ${ }^{2,3}$, Raluca Maxim ${ }^{2}$, Codruta Belibou $^{2,4}$, Codrina Ancuta $^{1,2}$ \\ ${ }^{\prime}$ Rheumatology and Rehabilitation Discipline, Grigore T. Popa University of Medicine and Pharmacy, Iasi \\ ${ }^{2}$ Rheumatology II Department, Clinical Rehabilitation Hospital, Iasi \\ ${ }^{3}$ Grigore T. Popa University of Medicine and Pharmacy, Iasi \\ ${ }^{4}$ Research Department, Clinical Rehabilitation Hospital, Iasi
}

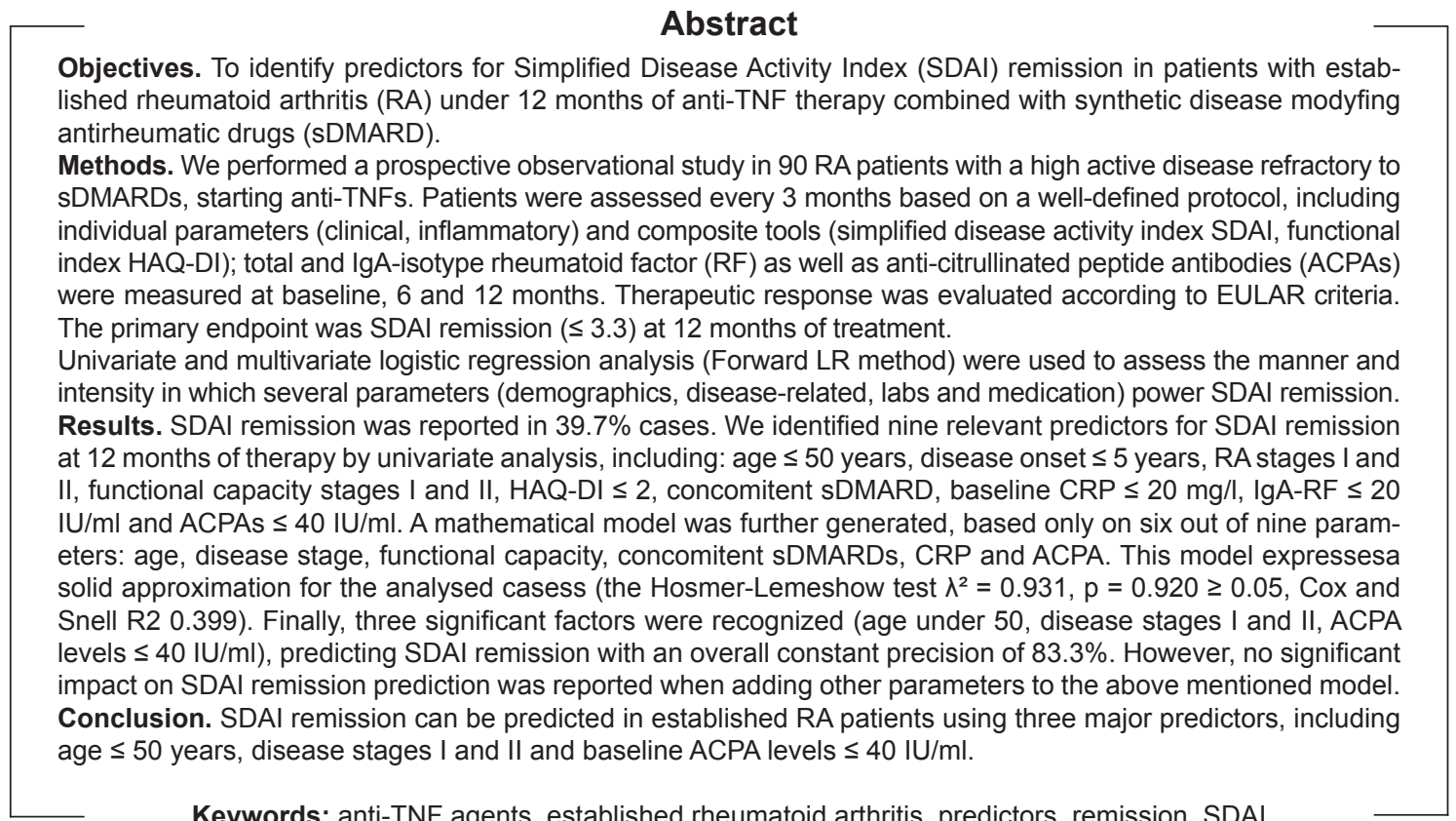

Keywords: anti-TNF agents, established rheumatoid arthritis, predictors, remission, SDAI

\section{INTRODUCTION}

Rheumatoid arthritis (RA) is a complex, multifactorial and heterogeneous disease with significant interpatient variation in symptoms, disease course and therapeutic response (1).

Recent advances in understanding the pathologic pathways of RA as well as the availability of emerging newer biological drugs and "treat-to-target" paradigm have redefined the clinical, functional and radiological outcomes of the disease, remission becoming an increasingly attainable goal (2). As the ultimate target of RA management is to achieve re- mission and to prevent the progression of joint damage, rheumatologists focus also on the durability of sustained remission and the identification of predictors, indication of monitoring and potential cessation of treatment in different RA settings (3).

Various definitions of RA remission have been developed and used over the last years, at least three of them being still employed: Disease Activity Score (DAS)-28 $\leq 2.6$, Simplified Disease Activity Index $(\mathrm{SDAI}) \leq 3.3$ and Clinical Disease Activity Index (CDAI) $\leq 2.8$ score $(4,5)$. Recently, the American College of Rheumatology (ACR) and the European-

Correspondence address:

Codrina Ancuta, Grigore T. Popa University of Medicine and Pharmacy, 16 Universitatii Street, Iasi

E-mail: codrina_ancuta@yahoo.com 
League Against Rheumatism (EULAR), together with the Outcome Measures in Rheumatology Initiative (OMERACT) jointly created a new definition of RA remission (6) - the ACR/EULAR provisional definition of RA remission - intended to be used in clinical trials.

SDAI adds the scores from five outcome measures including tender and swollen joint count, patient and physician global assessment of disease and $\mathrm{C}$-reactive protein (CRP). Three cut-off values are currently recognized for SDAI, 3.3 for remission, 11 for low disease activity (LDA), 26 for moderate disease activity (MDA), and more than 26 for high disease activity $(7,8)$.

It is widely accepted that SDAI correlates well with DAS28 and ACR response criteria, as well as with Health Assessment Questionnaire Disability Index (HAQ-DI) (9). Moreover, recently published data defined minor, moderate and major response on SDAI as $50 \%, 70 \%$, and $85 \%$ improvement, based on best agreement with ACR20, ACR50, and ACR70 responses, respectively (8). These definitions allow for various degrees of residual disease activity (2). Furthermore, reported remission rates vary depending on the definition used, from approximately $9 \%$ to $17 \%$ with the ACR criteria, $14 \%$ with CDAI or RAPID3, and $20 \%$ to $33 \%$ with DAS $(10,11)$.

The accuracy of different composite scores in classifying remission in RA may further be analyzed from the perspective of residual inflammatory activity detected by Doppler and power Doppler ultrasound: SDAI classification of remission is closer than DAS28 to the concept of an absence of inflammatory activity (12).

The therapeutic response varies considerably among patients with RA. Part of this fluctuation is dependent on patient characteristics, such as: age, sex, concomitant medication, body mass index or smoking status. In addition, the clinic response depends on disease activity and severity, the presence of autoantibodies, genetic background as well as cytokine levels and immune cells phenotype (B or T, Th1 or Th17) (13).

Anti-TNF agents induce an early therapeutic response, with a major impact on disease evolution and prognostic (14). However, not all patients respond to TNF inhibitors, and moreover a large number do not achieve remission. A recent study showed that approximately $30 \%$ of the patients with RA do not respond or do not tolerate the first anti-TNF agent, while around $50 \%$ of them suspend the therapy within the first 2 years (15).
Consequently, a domain of interest for both researchers and practitioners, promoted in nowadays medicine, is identifying the patients that will respond to a particular therapeutic agent and predictors of the response or of the non-response. Therefore, knowing the factors that can influence the therapeutic response to a certain biological agent allows for individualized management, disease evolution optimization, minimizing the risks and maximizing costefficiency.

With this background, we aimed to identify predictors for SDAI remission in active established RA forms treated with TNF inhibitors.

\section{PATIENTS AND METHODS}

We performed a 12-months prospective observational study in ninety consecutive RA patients (fulfilling the 1987 modified ACR diagnostic criteria for RA) with severe active disease (DAS28 > 5.1) despite sDMARD, requiring biologic therapy for optimal control of the disease.

Inclusion and exclusion criteria in the current study were derived from those endorsed by the Romanian National Board for Biologic Therapy in RA meaning treatment with anti-TNF agents as first line bDMARD in RA with high disease activity developing failure to previous therapy with at least two sDMARD (16).

Patients were further stratified according to their TNF inhibitor, 33 RA receiving adalimumab (ADA), 30 RA etanercept (ETA) and 27 RA infliximab (INF).

Classic doses and administration pathways were used as recommended by manufacturers for each biological agent; concomitant sDMARD including methotrexate (MTX), leflunomide (LEF), sulfasalazine (SSZ) and hydroxycloroquine (HCQ) were given in all the patients, while low doses of corticosteroids (CS) were permitted only if present at the baseline evaluation.

Standard assessments consisted of 28 tender and swollen joint count, patient reported outcomes (general health, pain, HAQ-DI), inflammation (C reactive protein, CRP, erythrocyte sedimentation rate, ESR), immunology (total rheumatoid factor and IgA isotype, anti-cyclic citrullinated peptide antibodies, ACPA), as well as disease activity scores (DA28ESR and SDAI). All parameters were performed regularly (every three months) except immunological tests which were evaluated every six months. Total RF was measured by latex immune-turbidimetric 
method (Cobas 800; Roche; cut-off value of $14 \mathrm{IU} /$ $\mathrm{ml}$ ) and IgA-RF by ELISA (cut-off $20 \mathrm{IU} / \mathrm{ml}$ ), while IgG-ACPA by Fluoro-Immuno-Enzymatic Assay (PHADIA250, PHADIA; cut-off $10 \mathrm{IU} / \mathrm{ml}$ ).

The main outcome of our study was SDAI remission $(\mathrm{SDAI} \leq 3.3)$ at follow-up were considered in remission, those with a SDAI ranging between 3.3 and 11 with low disease activity and between 11 and 26 as having moderate activity. Treatment response measured by EULAR-DAS28 criteria (14).

Local ethical committee approval and informed consent were obtained prior to enrollment.

\section{STATISTICAL ANALYSIS}

Univariate and multivariate logistic regression analysis (Forward LR) (odds-ratio with 95\% CI and 2-tailed p) were used to estimate the association between potential predictors and SDAI remission at 12 months; statistical analysis was carried out with SPSS16.

\section{RESULTS}

\section{Patients and remission rates}

Ninety long-standing RA, mainly female (81.1\%), with an average age of $55.56 \pm 10.75$ years, and an average disease duration of $10.9 \pm 6.2$ years were considered eligible and enrolled in our study. At inclusion, $74.4 \%$ patients were classified as RA stages III and IV, $72.2 \%$ had RF positivity and $60 \%$ ACPA positivity; average SDAI was $51.38 \pm 5.42$ and HAQ-DI was $2.02 \pm 0.33$ (Table 1).

During the first 12 months of treatment, 50 patients (56.8\%) achieved low disease activity, while 35 patients $(39.7 \%)$ were in remission according to SDAI criteria. Subgroup analysis showed: $42.4 \%$ remission for ADA, $36.6 \%$ for ETA and $40 \%$ for the INF group.

\section{Univariate regression analysis - predictors}

Although all clinical and lab variables as well as demographic and therapeutic data were independently analyzed by univariate logistic regression, only nine parameters were statistically significant ( $p$ $<0.05$ ) and further used as predictors for SDAI remission: onset before 50 years (OR:5.25, 95\% CI 2.27-12.14; $\mathrm{p}=0.000)$, a history of disease of at least 5 years (OR:5.53, 95\% CI 2.40-12.75; $\mathrm{p}=0.000$ ), RA stages I and II (OR:4.22, 95\% CI 1.99-8.94; $\mathrm{p}=0.000$ ), baseline functional status as reflected by
TABLE 1. Demographics, clinical and biological characteristics of RA patients at baseline

\begin{tabular}{|l|c|}
\hline RA characteristics & $55.56 \pm 10.75$ \\
\hline Age (years)* & $73(81.1 \%)$ \\
\hline Women** & $67(74.4 \%)$ \\
\hline RA stagesIII/IV** & $50(50.6 \%)$ \\
\hline Concomitant CS** & $23(25.6 \%)$ \\
\hline Concomitant DMARDs** & $28(31.1 \%)$ \\
\hline MTX & $39(43.3 \%)$ \\
\hline LEF & $18.53 \pm 2.82$ \\
\hline Others & $11.81 \pm 2.42$ \\
\hline TJC (28)* & $7.50 \pm 0.40$ \\
\hline SJC (28)* & $51.38 \pm 5.42$ \\
\hline DAS28-ESR* & $2.02 \pm 0.33$ \\
\hline SDAl & 66.61 \\
\hline HAQ-DI (0-3)* & 36.43 \\
\hline ESR (mm/1h)*** & 228.73 \\
\hline CRP (mg/liter)*** & 41.05 \\
\hline RF (IU/ml)** & 99.3 \\
\hline RF isotype A (IU/ml)*** & \\
\hline ACPA (IU/ml)*** & \\
\hline ACPA, & \\
\hline
\end{tabular}

ACPA, anti-cyclic citrullinated peptide antibody; CRP, C-reactive protein; DAS28, Disease Activity Score; DMARDs, Disease Modifying Antirheumatic Drugs; ESR, erytrocyte sedimentation rate; HAQ-DI, Health Assessment Questionnaire Disability Index; LEF, leflunomide; MTX, methotrexate; CS, corticosteroids; RA, rheumatoid arthritis; RF, rheumatoid factor; SJC, swollen joint count; SDAI, Simplified Disease Activity Index; $\mathrm{TJC}$, tender joint count; *, mean $+\mathrm{SD} ;{ }^{* *}, \mathrm{n}(\%) ; * * *$, mean

functional classes $\mathrm{I}$ and II and a HAQ-DI $\leq 2$ (OR:2.67, 95\% CI 1.07-6.68; $\mathrm{p}=0.022$; OR:2.39, 95\% CI 1.02-5.60; $\mathrm{p}=0.034$, respectively), baseline CRP $\leq 20 \mathrm{mg} / \mathrm{l}$ (OR:1.75, 95\% CI 0.81-3.73; $\mathrm{p}=0.041), \mathrm{IgA}-\mathrm{RF} \leq 20 \mathrm{IU} / \mathrm{ml}(\mathrm{OR}: 5.76,95 \% \mathrm{CI}$ $1.43-23.23 ; \mathrm{p}=0.002), \mathrm{ACPA} \leq 40 \mathrm{IU} / \mathrm{ml}(\mathrm{OR}: 1.99$, 95\% CI 0.95-4.17; $\mathrm{p}=0.047)$ and concomitant $\mathrm{sD}$ MARDs (OR:5.50, 95\% CI 1.36-22.13; $\mathrm{p}=0.003$ ) (Table 2). Gender, clinical individual parameters and ESR were not predictors for treatment response our study $(\mathrm{p}>0.05)$.

\section{Multivariate regression analysis (Forward LR)}

A mathematical model was generated subsequently, based on several parameters, as follows: age $\leq$ 50 years, RA disease stages I and II, functional capacity I and II, concomitent sDMARD, baseline CRP $\leq$ $20 \mathrm{mg} / 1$ and ACPA $\leq 40 \mathrm{IU} / \mathrm{ml}$ (Table 3). Therefore, our model represents a solid approximation for the analysed case (the Hosmer-Lemeshow test $\lambda^{2}=$ $0.931, p=0.920 \geq 0.05$, Cox and Snell $R^{2} 0.399$ ).

Finally, only three significant predictors were selected: age $\leq 50$ years, RA stages I and II and the ACPA levels $\leq 40 \mathrm{IU} / \mathrm{ml}$ at baseline. These factors support a correct prediction of SDAI remission, with an overall precision of $83.3 \%$. All other analysed 
TABLE 2. Significant predictors for SDAI remission

\begin{tabular}{|c|c|c|c|}
\hline Parameter & $\begin{array}{l}\text { Spearman } \\
\text { coefficient }\end{array}$ & p & OR, IC $95 \%$ \\
\hline Age $\leq 50$ years & 0.463 & 0.000 & $5.259,2.277-12.147$ \\
\hline $\begin{array}{l}\text { Disease onset } \leq 5 \\
\text { years }\end{array}$ & 0.492 & 0.000 & $5.536,2.402-12.758$ \\
\hline Disease stagesI/II & 0.420 & 0.000 & $4.225,1.995-8.947$ \\
\hline $\begin{array}{l}\text { Functional capacity } \\
\text { I/II }\end{array}$ & 0.241 & 0.022 & $2.678,1.073-6.682$ \\
\hline$H A Q-D I \leq 2$ & 0.224 & 0.034 & $2.391,1.020-5.605$ \\
\hline ConcomitantsDMARD & 0.311 & 0.003 & $5.500,1.366-22.137$ \\
\hline CRP levels $\leq 20 \mathrm{mg} / \mathrm{l}$ & 0.147 & 0.041 & $1.750,0.819-3.739$ \\
\hline $\begin{array}{l}\text { RF IgA levels } \leq 20 \text { UI/ } \\
\mathrm{ml}\end{array}$ & 0.321 & 0.002 & $5.768,1.432-23.234$ \\
\hline $\begin{array}{l}\text { ACPA levels } \leq 40 \text { UI/ } \\
\mathrm{ml}\end{array}$ & 0.194 & 0.047 & $1.994,0.952-4.177$ \\
\hline
\end{tabular}

TABLE 3. Variables included in the predictive model for SDAl remission

\begin{tabular}{|l|l|l|c|c|c|}
\hline & & Score & df & Sig. \\
\hline Initially & Variables & Age $\leq 50$ years & 19.221 & 1 & .000 \\
\cline { 3 - 6 } & Disease stages I/II & 23.061 & 1 & .000 \\
\cline { 3 - 6 } & $\begin{array}{l}\text { Functional capacity } \\
\text { I/II }\end{array}$ & 12.449 & 1 & .000 \\
\cline { 3 - 6 } & MTX addition & 2.529 & 2 & .282 \\
\cline { 3 - 6 } & LEF addition & 2.005 & 1 & .157 \\
\hline & Other sDMARD & .485 & 1 & .486 \\
\hline & CRP levels $\leq 20 \mathrm{mg} / \mathrm{I}$ & .769 & 1 & .381 \\
\hline & $\begin{array}{l}\text { ACPA levels } \leq 40 \\
\text { IU/ml }\end{array}$ & 17.931 & 1 & .000 \\
\hline
\end{tabular}

ACPA, anti-cyclic citrullinated peptide antibody; CRP, C-reactive protein; sDMARD synthetic Disease Modifying Antirheumatic Drugs; HAQ-DI, Health Assessment Questionnaire Disability Index; LEF, leflunomide; MTX, methotrexate; RF, rheumatoid factor; SDAl, Simplified Disease Activity Index.

predictors had no positive impact on the proposed mathematical model (Table 4).

\section{DISCUSSION}

Given the destructive and disabling nature of RA, the risk of secondary effects, considerable costs and variable therapeutic response, it is mandatory to identify predictive factors among demographic, clinic, biologic (inflammatory and immunologic), imagistic and genetic parameters in order to define the steps required to obtain remission or low disease activity status.

The topic of therapeutic response to different therapies, either sDMARDs or bDMARDs, was largely addressed in the last decade; moreover, a significant number of studies were directed towards identifying biomarkers of response to TNF inhibitors and B-cell depleting agent rituximab (17-22).
TABLE 4. Significant factors in our predictive model for SDAl remission

\begin{tabular}{|l|l|c|c|c|c|c|c|}
\hline & & B & S.E. & Wald & df & Sig. & Exp(B) \\
\hline Step 1 & $\begin{array}{l}\text { Disease } \\
\text { stages I/II }\end{array}$ & -2.445 & .557 & 19.270 & 1 & .000 & .087 \\
\cline { 2 - 8 } & Constant & 1.293 & .302 & 18.358 & 1 & .000 & 3.643 \\
\hline \multirow{5}{*}{ Step 2 } & $\begin{array}{l}\text { Age } \leq 50 \\
\text { years }\end{array}$ & -2.013 & .577 & 12.176 & 1 & .000 & .134 \\
\cline { 2 - 8 } & $\begin{array}{l}\text { Disease } \\
\text { stages I/II }\end{array}$ & -2.358 & .613 & 14.817 & 1 & .000 & .095 \\
\cline { 2 - 8 } & Constant & 1.988 & .415 & 23.007 & 1 & .000 & 7.303 \\
\hline \multirow{3}{*}{ Step 3 } & $\begin{array}{l}\text { Age } \leq 50 \\
\text { years }\end{array}$ & -2.121 & .636 & 11.112 & 1 & .001 & .120 \\
\cline { 2 - 8 } & $\begin{array}{l}\text { Disease } \\
\text { stages I/II }\end{array}$ & -2.142 & .665 & 10.387 & 1 & .001 & .117 \\
\cline { 2 - 8 } & $\begin{array}{l}\text { ACPA levels } \\
\leq 40 \text { IU/ml }\end{array}$ & -1.834 & .618 & 8.789 & 1 & .003 & .160 \\
\cline { 2 - 8 } & Constant & 2.666 & .537 & 24.653 & 1 & .000 & 14.380 \\
\hline
\end{tabular}

We developed a prediction model for SDAI remission in patients with established RA, based on three main parameters (age at onset, disease stage and ACPA status), that successfully classified over $83.3 \%$ of patients in our cohort; thus, patients with a disease onset before 50, a RA stage I or II, and low ACPA at baseline (under $40 \mathrm{IU} / \mathrm{ml}$ ) were most likely to achieve SDAI remission after a 12-months of follow-up under anti-TNFs.

The proposed mathematical model for predicting SDAI remission after 12 months of TNF inhibitors therapy, based on independent factors, is appropriatefor a particular disease pattern, with an associated factor of 0.399 (Cox and Snell).

In clinical practice, this model is relevant fora well-defined RA subtype: age $\leq 50$ years, disease stage I/II, functional capacity I/II, low CRP levels $(\leq 20 \mathrm{mg} /)$ and mild immunologically syndrome (ACPA levels $\leq 40 \mathrm{IU} / \mathrm{ml}$ ), concomitant sDMARD.

Making the personalized choice of RA treatment in the era of targeted therapy is commonly based on optimal patient outcomes. Therefore, matching patients to a specific drug is powered not only by correct assessment of remission but also by identifying and validating predictors for response. Rheumatologists currently focus on different ways to control disease and assess remission, several standardized measurement tools (DAS28, CDAI, SDAI, RAPID3, ACR/ EULAR) and wide ranging remission rates being recognized $(4,6,10,11)$.

To our knowledge no previous study has addressed the issue of SDAI remission in the particular settings of established RA. Although we used SDAI remission at a single time point (12 months) as the 
individual criterion to evaluate treatment response, three independent predictors were finally available: age, RA stage and ACPA levels. However, a wider panel of biomarkers, laboratory as well as imaging should be examined.

We accept that it still premature to change the landscape of risk stratification in established RA based on our predictive model, but at this moment is best at predicting those patients who are likely to achieve SDAI remission at 12 months. Future work is required to optimize this approach.

Availability of newer therapies is doubled by a change in rheumatologists thinking changed the tre- atment paradigm in RA. The clinical rationale for the treat to target approach as well as the concept of predicting remission in established RA are useful to tailor personalized treatment levels.

\section{CONCLUSION}

SDAI remission can be predicted in patients with established RA using three relevant predictors: age $\leq$ 50 years, disease stages I or II, and baseline ACPA levels $\leq 40 \mathrm{IU} / \mathrm{ml}$.

\section{REFERENCES}

1. Mease P.J. The potential roles for novel biomarkers in rheumatoid arthritis assessment. Clin Exp Rheumatol. 2011; 29(3):567-574.

2. Smolen J.S., Aletaha D., Bijlsma J.W.J., et al. Treating rheumatoid arthritis to target: recommendations of an international task force. Ann Rheum Dis. 2010; 69:631-637.

3. van Tuyl L.H., Felson D.T., Wells G., et al. Evidence for predictive validity of remission on long-term outcome in rheumatoid arthritis: a systematic review. Arthritis Care Res (Hoboken). 2010; 62(1):108-117.

4. Shammas R.M., Ranganath V.K., Paulus H.E. Remission in rheumatoid arthritis. Curr Rheumatol Rep. 2010; 12:355-362.

5. Pinals R.S., Masi A.T., Larsen R.A. Preliminary criteria for clinical remission in rheumatoid arthritis. Arthritis Rheum. 1981; 24:13-18.

6. Felson D.T., Smolen J.S., Wells G., et al. American College of Rheumatology/European League Against Rheumatism provisional definition of remission in rheumatoid arthritis for clinical trials. Arthritis Rheum. 2011; 63:573-586.

7. Aletaha D., Smolen J.S. The Simplified Disease Activity Index and Clinical Disease Activity Index to monitor patients in standard clinical care. Rheum Dis Clin North Am. 2009; 35:759-772.

8. Aletaha D., Martinez-Avila J., Kvient T.K., et al. Definition of treatment response in rheumatoid arthritis based on simplified and the clinical disease activity index. Ann Rheum Dis. 2012; 71:1190-1196.

9. Smolen J.S., Breedveld F.C., Schiff M.H., et al. A simplified disease activity index for rheumatoid arthritis for use in clinical practice. Rheumatology. 2003; 42:244-257.

10. Sokka T., Hetland M.L., Makinen H., et al. Remission and rheumatoid arthritis. Data on patients receiving usual care in twenty-four countries. Arthritis Rheum. 2008; 58:2642-2651.

11. Gaujoux-Viala C., Mouterde G., Baillet A., et al. Evaluating disease activity in rheumatoid arthritis: Which composite index is best? A systematic literature analysis of studies comparing the psychometric properties of the DAS, DAS28, SDAI and CDAI. Joint Bone Spine. 2012; 79(2):149-155.

12. Balsa A., de Miguel E., Castillo C., et al. Superiority of SDAI over DAS-28 in assessment of remission in rheumatoid arthritis patients using power Doppler ultrasonography as a gold standard. Rheumatology. 2010; 49:683-690.

13. Daien C.I., Morel J. Predictive facors of response to biological disease modifying antirheumatic drugs: towards personalized medicine. Mediators of inflammation 2014;1-17.

14. Schoels M., Aletaha D., Smolen J.S., Wong J.B. Comparative effectiveness and safety of biological treatment options after tumour necrosis factor a inhibitor failure in rheumatoid arthritis: systematic review and indirect pairwise metaanalysis. Ann Rheum Dis 2012; 71:1303-1308.

15. Papagoras C., Voulgari P.V., Drosos A.A. Strategies after the failure of the first anti-tumor necrosis factor-alpha agent in rheumatoid arthritis. Autoimmun Rev 2010; 9:574-582.

16. Bolosiu H., lonescu R., Chirieac R., et al. Ghidul de tratament al poliartritei reumatoide. Revista Romană de Reumatologie. 2011; XX (1), 36-53.

17. Gottenberg J.E., Ravaud P., Cantagrel A., et al. Positivity for anticyclic citriulluinated peptide is associated with a better response to abatacept: data from the 'Orencia and Rheumatoid Arthtiris' registry. Ann Rheum Dis 2012;71:1815-1819.

18. Burmester G.R., Feist E., Kellner H., et al. Effectiveness and safety of the interleukin 6-receptor antagonist Tocilizumab after 4 and 24 weeks in patients with active rheumatoid arthritis: the first phase Illb real-life study (TAMARA). Ann Rheum Dis 2011; 70:755-759.

19. Silverman G.J., Schwartzman S., Townsend M., et al. Identification of biomarkers for enhanced benefit to rituximab in rheumatoid arthritis: role of autoantibodies and inflammatory markers. Arthritis Rheum 2009; 60(S10):1680-1681.

20. Sellam J., Hendel-Chavez H., Rouanet S., et al. B Cell activation biomarkers as predictive factors for the response to rituximab in rheumatoid arthritis: a six-month,national, multicenter, open-label study. Arthritis Rheum 2011;63:933-938.

21. Nam J., Emery P. The role of biomarkers in the management of patients with rheumatoid arthritis. Current Rheumatology Reports 2009;11:371-377.

22. Emery P., Gabay C., Kraan M., Gomez-Reino J. Evidence based review of biologic markers as indicators of disease progression and remission in rheumatoid arthritis. Rheumatol Int 2007; 27:793-806. 